\title{
Determinants of Electric Car Sales in Europe
}

\author{
Richard Kovárník ${ }^{1}$ and Michaela Staňková ${ }^{* *}$ \\ ${ }^{1}$ Mendel University in Brno, Faculty of Business and Economics, Zemědělská 1, 61300 Brno, Czech \\ Republic; Email: xkovarn1@node.mendelu.cz \\ ${ }^{2}$ Mendel University in Brno, Faculty of Business and Economics, Department of Statistics and \\ Operation Analysis, Zemédělská 1, 61300 Brno, Czech Republic; Email: \\ michaela.stankova@mendelu.cz
}

*Corresponding Author: Michaela Staňková

Received: 15 June 2021; Revised: 20 October 2021; Accepted: 3 November 2021; Published: 24 November 2021

Abstract: This article deals with determining statistically significant factors affecting the sale of battery electric vehicles in different European countries. Typical representative countries were selected on the basis of cluster analysis. The input data for multiple regression models and vector autoregressive models include data for the last decade and thus essentially cover the complete history of the electric car market. Attention is paid not only to the European leader but also to countries with a lower share of electric cars. The results of this study show the existence of a common factor in the countries with different development trends in the battery electric vehicle market. However, differences among individual countries are generally so significant that the identified factors vary from country to country.

Keywords: Battery electric vehicle, Europe, cluster analysis, significant factors

\section{Introduction}

Although the first successful electric car was introduced earlier than a car equipped with an internal combustion engine, their popularity has grown only over the last decade. Currently, the popularity of electric cars is growing significantly, supported by the interest of the majority of developed countries. Today, almost every country in Europe envisages some sort of plan to reduce the use of conventional vehicles. According to [1], this effort is motivated mainly by increasing air pollution and by environmental needs in general. The proliferation of electric cars could also help reduce energy consumption in transport and improve the quality of life of the population in large cities.

Europe (and in particular some countries) is heavily dependent on the automotive industry. Companies such as car manufacturers and plants manufacturing accessories and components for 
internal combustion engines are among the largest businesses and employers in Europe. The European Commission states that 13.8 million Europeans work in a sector directly or indirectly linked to the automotive. Furthermore, the turnover generated by automotive industry accounts for more than $7 \%$ of the GDP of the entire European Union. The automotive industry is critical for national governments for one sad reason, and that is traffic accidents. Through their actions, the governments of individual states interfere indirectly in this industry (see [2]). Manufacturers are trying to reduce the number of traffic accidents by developing self-driving vehicles. Autonomous cars should be able to eliminate sensing and perception errors and will not be subject to the influence of drugs or alcohol.

The automotive industry is key to Europe's prosperity and countries such as the Czech Republic and Germany are heavily dependent on this sector. However, the transition to electromobility is also challenging in these countries and will bring about a number of changes the individual economies must prepare for. In general, it can be stated that at the present time, Europe is not the most important market for electric car manufacturers. It still lags behind the North American and especially Asian markets.

The main aim of this article is to identify statistically significant factors influencing the sale of electric cars in selected European countries. Individual countries will be selected using cluster analysis, which enables creating groups of countries with similar characteristics and choosing one representative for each country to represent the group. The models will be estimated individually for these individual countries in order to be able to compare any possible differences between individual countries.

\section{Identification of Potential Factors}

The electric car market is undoubtedly affected by a number of factors, which may vary from country to country. However, it can be assumed that it will be possible to find some common factors across countries with different development trends in the electric car industry. The sale of internal combustion cars was chosen as the first potential factor influencing the sale of electric cars. There is currently no study confirming the connection between the sales of internal combustion engine cars and electric cars in selected European countries, but it can be assumed that a statistically significant link could be found between the sales of each type of car.

[3] focused their study on the role of psychological factors that influence the decision-making process when buying an electric car. They found that electric vehicles are strongly associated with identity, faith and personal values and are not seen just as a means of transport. [4] aimed to examine the factors influencing the consumer purchasing decision when buying a new car. Their study was conducted for the Polish market. In their study, they focused directly on electric cars. 
One of the results of their study was the finding that approximately $75 \%$ of the Polish population thinks that electric vehicles are too expensive, but at the same time admit they would be willing to pay more for an electric car than for a conventional vehicle of the same class. Based on this study, the average wage was identified as the second potentially significant factor influencing the sale of electric cars.

A significant correlation can be observed between the value of gross domestic product per capita (GDP per capita) and the market share of electric cars in a given country. In 2018, approximately half of the Member States of the European Union had a market share of electric cars of less than $1 \%$. At the same time, the gross domestic product per capita of all these countries including the Czech Republic was below $€ 29,000$ per year. On the other hand, a market share exceeding 3.5\% was achieved only in countries with an annual GDP higher than €42,000. Norway is considered to be the reference market, reaching approximately a $40 \%$ share of electric vehicles in 2018. At the same time, the country's gross domestic product was $€ 73,200$, which was about twice the European average. Other Scandinavian countries also ranked behind Norway, still achieving some of the highest GDP values in Europe.

The link between GDP and the car market was demonstrated in a study by [5]. This study deals with the microeconomic and macroeconomic factors influencing the car market and the state of the car market in Spain. It can be assumed that similar links observed at the level of GDP and the entire automotive industry could be confirmed even when focusing directly on the electric car market. Therefore, the value of GDP can consider another potentially significant factor influencing the sale of electric cars.

Probably the most important and most discussed part of an electric car is its battery. The trend in the price of batteries and its impact on the electric car market were addressed e.g.in a study by [6]. The study considers the decrease in battery prices and thus the reduction in production costs of electric cars to be one of the main reasons for the growing interest in electric cars. Moreover, the study states that for electric cars to be fully price-competitive with conventional internal combustion vehicles, the price of the so-called battery pack needs to fall below $\$ 150$ per $\mathrm{kWh}$. [7] assume that the growing demand for electric cars will be accompanied not only by a falling price for batteries, but also by a rising oil and fuel prices. Thus, the price of the battery pack and the price per barrel of oil are considered to be other two potential factors influencing the sale of electric cars.

In their study [8] pointed out the often-neglected role of the brand in the eyes of electric car customers. This is the area of the so-called brand loyalty. Customers tend to choose a brand they identify with. While those interested in classic internal combustion cars tend to be more conservative, those interested in electric cars, on the other hand, are often considered pioneers and visionaries. In the field of electric cars, Tesla Inc. plays a specific role, as, according to the results 
of the study, it is associated with electric cars by almost $30 \%$ of the respondents in Canada. Furthermore, $40 \%$ of respondents described Tesla as a company representing the future of electric cars. It shall also be noted that approximately half of the respondents who stated that they knew Tesla's products answered that Tesla had increased their confidence in electromobility. The results show that the perception of a brand can have a significant impact on the development of electromobility and thus on the number of units sold. The importance of this company is also underlined by the number of charging stations it has built. At present, there are over 20,000 socalled superchargers or fast charging stations around the world belonging to this company.

The last potential factor considered in our article is the value of the Tesla share. This variable provides a dual perspective. If we follow the findings of [8] and consider this variable as certain consumer expectations and trust in electromobility, this variable is also supposed to affect the sales of electric cars. From a classic economics point of view, however, the level of sales should affect the value of Tesla shares. Nevertheless, Tesla Inc. has a wide range of activities and electric vehicles do not represent its only product; therefore, the value of its shares does not depend only on the sales of electric vehicles. There is currently no comprehensive study available to analyse in more detail the trend in the relationship between these two variables. For this reason, the variable of the value of the Tesla share will be given special attention to in this article. First, the possible causality of the relationship will be verified using a vector autoregression model. If Tesla's share price is proven to influence car sales, this variable will be used in the multiple models.

\section{Data and Methods}

This analysis is based on two datasets. Cross-sectional data (2020) for individual European countries are used to identify groups (clusters) by means of cluster analysis. A total of seven variables were selected: battery electric vehicle sales per capita, sales of internal combustion engine vehicles per capita, GDP per capita, average annual income, number of charging stations per capita, happiness index and $\mathrm{CO}_{2}$ value per capita. A total of 31 countries are included in the cluster analysis, based on the available data. Using cluster analysis, countries with available data are divided into homogeneous groups according to common characteristics as in [9]. As in [10], Euclidean distance is used as a pairwise distance between pairs of objects; standardization is not necessary because variables such as GDP have been converted per capita. To ensure robustness of the results, different approaches are used for calculating the distance between clusters: the shortest distance, the longest distance, the average distance, and Ward distance are used. Technical details regarding cluster analysis can be found in [11]. Using the identified clusters, one country is selected for each group, for which statistically significant factors will be examined. 
The identification of significant factors is carried out via time series analysis. The input data cover the last ten years and thus basically the complete history of the electric car market. More precisely, this refers to the period from the 1 st quarter of 2010 to the 4 th quarter of 2020 . All the data come mainly from national databases or verified sources. The number of cars sold was obtained mainly from the official registers of selected countries. Macroeconomic indicators were obtained from the official statistical offices of a given country.

Based on the literary research, a total of six variables were selected which may have a statistically significant effect on the sale of electric cars. Three of these variables are individual for each selected country: GDP per capita, the average monthly wage and sales of internal combustion engine vehicles. As the models are estimated separately for each country, the values of GDP per capita and the average monthly wage were kept in the national currency. The other three variables - i.e., the price of oil per barrel (USD), the value of Tesla shares (USD), the price of batteries or the so-called battery pack (USD per kWh) - are common to all selected countries.

A multiple regression model is used to determine the possible statistical significance of the potential factors influencing sales, similar to [12] and [13]. The t-test is used to verify the statistical significance of the individual model parameters, and the F-test to verify the significance of the model itself like in [14]. When verifying the model, attention is paid to the most common problems, see [15].

Possible multicollinearity between explanatory variables is verified using the variance inflation factor (VIF) values. The assumption of the correct specification of the model is verified using an LM test. The White test is used to detect possible heteroskedasticity of residuals, while Chi-Square test enables verification of the assumption of a normal distribution of residuals. The Durbin-Watson test (lag equal to one) and the Ljung-Box test (lag equal to four) are used to detect possible autocorrelation of residuals. Finally, attention is also paid to the seeming dependence in time series. Since the time series are non-stationary, the cointegration of the time series is verified using the KPSS test. Technical details on the techniques described above can be found in [16].

Before compiling the multiple models, the existence of the link between the electric car sales variable and the value of Tesla shares are verified. Using a vector autoregressive (VAR) model, it is possible to verify a possible causal relationship between these two variables. We will use the Granger causality test as [17] did to test the null hypothesis that $X$ does not Granger-cause $Y$. More detailed information on regression analysis and VAR models is presented in [18].

All the above procedures are performed using Matlab (version 2020b). 


\section{Results}

\subsection{Results of Cluster Analysis}

Ward's method was chosen in the cluster analysis; the resulting dendrogram is shown in Fig. 1.

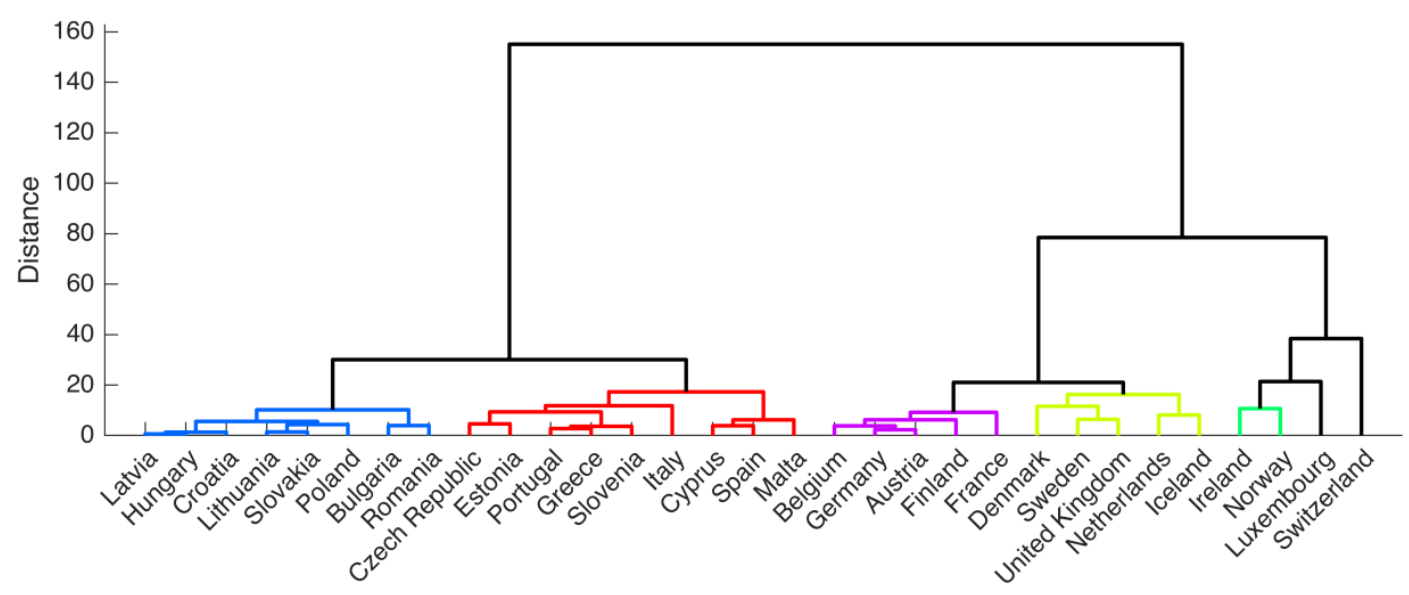

Fig. 1 Dendrogram. Source: authors

The first cluster (blue) of countries are less developed countries, especially in Eastern Europe. These countries combine similar values of macroeconomic indicators and sales of both internal combustion and electric vehicles. The existing infrastructure of charging stations is at a similar level. The cluster is represented by Poland, which is currently the largest market for electric cars in Eastern Europe. The share of newly sold electric cars in Poland is $0.8 \%$.

The second cluster (red) consists of countries with a higher economic level than the previous cluster. The average GDP per capita in these countries is $€ 19,640$. The countries also have a similar infrastructure of charging stations, share of electric cars and level of air pollution. This cluster is represented by the Czech Republic as a country heavily dependent on automotive and the related industries.

The third cluster (purple) consists mainly of Western European countries. These countries have already attained high economic level and electromobility is already more established here. The share of electric cars within newly registered vehicles already exceeds $3 \%$ in all these countries and in some cases, it's up to $6 \%$. The group is represented by Germany, as a representative of the automotive industry and the economic leader in Europe.

The fourth cluster (yellow) consists of Northern and Western Europe. The countries are again characterised by high economic maturity, which is reflected in the average value of GDP per capita of $€ 40,676$. In these countries, electromobility is already at a high level and the share of newly registered electric cars in the total number of vehicles ranges from $7 \%$ to $26 \%$. The cluster is represented by the United Kingdom as a country with a strong tradition in the automotive industry and a rapidly developing degree of electromobility. 
The last group are the most economically developed countries in Europe (i.e. green cluster merged with Luxembourg and Switzerland), where the average value of GDP per capita exceeds $€$ 65,000 . Paradoxically, this group shows the highest level of air pollution of all clusters. This cluster is represented by Norway, which is a leader in terms of its share of electric cars, which has already exceeded $50 \%$.

For each cluster, the aforementioned representative is subjected to further analysis. The analysis thus includes five countries that differ in the current state and popularity of electric cars as well as in the legislative framework established for alternative powered vehicles. Norway as the main customer in terms of electric cars is one of the selected countries. Another selected country is the Czech Republic, which is the opposite of Norway in terms of the use of electric cars, as their sales in the Czech Republic are among the lowest in Europe. Despite the relatively low numbers compared to other countries, a clear increase in the number of units sold can be observed. Another country is the Federal Republic of Germany. Germany represents the middle ground between the two different approaches to electromobility. Although Germany is a strong and developed economy, it holds an average position in terms of sales of electric cars. The situation in Germany is also strongly affected by the actions of local car manufacturers which have been forced by the European Union since 2009 to reduce CO2 emissions. The strong position within the country of traditional car manufacturers such as BMW, Mercedes-Benz, VW and others, can thus different effects on the development of electromobility in the country [19].

Poland represents a relatively large market, which, however, is not nearly as progressive as the aforementioned Norway and suggests that the size of the market may not be the main criterion in the number of vehicles sold. Another representative is the United Kingdom, which showed a fourfold increase in the number of registered electric cars in 2020 compared to 2019. The rapidly developing electromobility in the country is also evidenced by the developed infrastructure of charging stations, which has already exceeded 33,000 public charging stations.

\subsection{Significant Factors and Granger Causality Results}

Due to the non-stationarity of the economic time series and the observed autocorrelation (lag equal to four), the time series were seasonally adjusted (using X-12-ARIMA) and converted into differences, where the assumptions for the VAR model were met. The results of the VAR models are presented in Table 1. In the case of Poland and the Czech Republic, the VAR(2) model was chosen, while for other countries, the VAR(4) model was chosen. These models were chosen due to the lowest values of information criteria and the absence of autocorrelation in residuals. Based on all p-values, it can be uniformly stated that for all countries, two-way Granger causality between the sale of electric cars and the Tesla stock price was confirmed. 
Table 1 Granger causality results via VAR models for individual countries. Source: authors

\begin{tabular}{cccc}
\hline Country & VAR lags & Tesla stock Granger-cause sales & Sales Granger-cause Tesla stock \\
\hline Poland & up to 2 & Yes (p-value 0.0464) & Yes (p-value 0.0002) \\
\hline Czech Rep. & up to 2 & Yes (p-value <0.0001) & Yes (p-value 0.0487) \\
\hline Germany & up to 4 & Yes (p-value 0.0453) & Yes (p-value 0.0417) \\
\hline UK & up to 4 & Yes (p-value 0.0053) & Yes (p-value 0.0001) \\
\hline Norway & up to 4 & Yes (p-value <0.0001) & Yes (p-value 0.0018) \\
\hline
\end{tabular}

A multiple regression model was subsequently created to identify statistically significant parameters in accordance with [20]. In addition to the Tesla share price, the influence of other variables was demonstrated (see Table 2). In the case of the battery pack price and the sale of internal combustion (IC) cars, a negative effect on the sale of electric cars was demonstrated. The other variables had a positive effect. Within the estimated models, the principle of cointegration was used and the constructed models did not seriously violate any of the assumptions of the classical linear regression model. In all models, the variable of average monthly salary had to be omitted due to multicollinearity.

Table 2 Overview of selected factors' significance in individual countries. Source: authors

\begin{tabular}{cccccc}
\hline Country & GDP & IC vehicle sales & Barrel of oil price & Battery pack & Tesla stock \\
\hline Poland & Yes & No & Yes & Yes & Yes \\
\hline Czech Rep. & Yes & Yes & No & No & Yes \\
\hline Germany & Yes & No & Yes & Yes & Yes \\
\hline UK & No & No & Yes & Yes & Yes \\
\hline Norway & No & Yes & Yes & Yes & Yes \\
\hline
\end{tabular}

\section{Discussion}

The current development of electromobility not only in Europe but also in the world varies dramatically between individual countries. Although the European market is considered to be almost uniform from the point of view of car manufacturers, the situation is already diametrically different from the perspective of electromobility. Significant differences between countries can be observed across the European continent. These differences are influenced by several factors; not all of them can be quantified or expressed in any way appropriate for econometric processing. These factors include the attitudes, opinions and personal preferences of each individual customer when making purchasing decisions and choosing between an electric vehicle and a conventional vehicle. 
On the other hand, like any other market, the electric vehicle market is largely influenced by the economic level of a given country, i.e., by its population and by the macroeconomic indicators that show this level. This situation was reflected in the cluster analysis, where the countries in the created clusters differ mainly by the differing popularity of electric vehicles but also by their different economic situation. It can be stated that the results of this analysis accurately reflect the current reality and group countries precisely by more than just their economic level.

For each cluster, one representative was selected, which was subjected to a more detailed analysis regarding the sale of electric cars. Based on the ideas in [8], attention was focused on possible non-economic factors influencing the purchase of an electric car. The study by [8] focused on the role of brand perception in purchasing decisions and especially on the importance of the Tesla brand for consumers. The study points out that a large proportion of consumers, when thinking of an electric car, think of Tesla cars, and for them, this company is an entity that represents the future of electromobility. Although it is difficult to accurately quantify psychological factors, the results of the Granger causality show that in selected countries, there is a two-way relationship between the value of Tesla shares and the sale of electric cars. Furthermore, it was found that in more developed countries with greater popularity in electromobility (i.e. Norway, the United Kingdom, Germany) there is an interconnection between these variables in the longer term. On the contrary, in Poland and the Czech Republic, a dynamic link was demonstrated only up to a period of two quarters.

The Tesla share price variable was also considered in all regression models. It can thus be said that the wealth of individuals and the whole country are strongly interconnected here. It was difficult to choose which of these two variables is more representative. Due to the fact that most electric cars are purchased by companies due to tax benefits (and also taking into account VIF values), GDP per capita was included in the models.

The positive influence of the wealth of an individual or the economic development of the whole country was also observed by [5]. However, the results of our analyses show that the impact of GDP is statistically significant, especially in those countries where the current economic level is not very high (like the Czech Republic). From this point of view, the results of cluster and regression analysis are corresponded to the findings of [5]. Therefore, it can be stated that in less affluent countries (i.e. less affluent individuals, for whom buying an expensive vehicle is sometimes financially impossible), the influence of GDP is strong, and in countries where GDP per capita exceeds $€ 60,000$ the link is already insignificant.

The results of our article confirmed the ideas of [6], since battery packs (as the main component of an electric vehicle) appeared in all countries (except the Czech Republic) among the statistically significant factors influencing the sale of electric cars. [6] mention the limit of 150 USD 
per $\mathrm{kWh}$ as the point at which electric vehicles become competitive and comparable in price with similar vehicles of the conventional type. According to the input data, this value was achieved in 2019. And it was during this period that an increase in sales of electric vehicles could be observed in all countries except the Czech Republic. The question remains whether there is still room to reduce this price, which has already fallen from ca. USD 1,200 to USD 130 per $\mathrm{kWh}$ and has thus reached the price level of traditional cars, or whether it will be necessary to look for another way to increase the competitiveness of electric cars, which most consumers consider precisely on the basis of the purchase price of the vehicle.

The results of our models are also consistent with the study by [7], Because the price per barrel of oil has appeared among the statistically significant factors in all countries except the Czech Republic. The Czech Republic has generally emerged as a very different country when identifying the factors influencing the sale of electric cars. In addition to the above, only the Czech Republic and Norway showed a statistically significant negative link between sales of internal combustion cars and electric cars. And from a general point of view, the combination of identified factors for the Czech Republic is completely different in comparison with other selected countries. Revealing the specifics of the Czech Republic and thus the whole cluster could be a topic of further research.

The upward trend in the sale of electric cars can also be influenced by support provided by the state in the form of direct or indirect subsidies. Based on this assumption, it would be appropriate to include a variable that would appropriately represent this fact in the models. Here, however, we encounter the problem of quantifying such a variable. Due to the variability of different forms of subsidies in individual states, it would be very difficult to capture individual forms of subsidies in one variable and all in quarterly observations. For this reason, this variable is not included in the model.

\section{Conclusion}

The results of this article show that besides other factors influencing the sales of electric cars, psychological factors also play an important role. Future expectations and trust in electromobility can be successfully captured with the Tesla share price. However, country specificities should currently be taken into account when examining sales of battery electric vehicle. The results of this article revealed not only statistically significant factors, but also possible similarities between countries with different development trends in the electric vehicle market. It is possible that over time, differences between countries will decrease and even more common factors will be identified than just the price of Tesla shares. This question may only be answered by further research in this field. 


\section{Acknowledgments}

This article was supported by grant No. PEF/TP/2021002 of the Grant Agency IGA PEF MENDELU.

\section{References}

[1] Rosato, A., Sibilio, S., Ciampi, G., Entchev, E. \& Ribberink, H. (2017). Energy, Environmental and Economic Effects of Electric Vehicle Charging on the Performance of a Residential Building-integrated Micro-trigeneration System. Energy Procedia 111, 699-709. DOI: 10.1016/j.egypro.2017.03.232.

[2] Stojanová, H. \& Blašková, V. (2018). Cost benefit study of a safety campaign's impact on road safety. Accident Analysis \& Prevention 117, 205-215. DOI: 10.1016/j.aap.2018.04.012.

[3] Hasan, S. \& Simsekoglu, Ö. (2020). The role of psychological factors on vehicle kilometer travelled (VKT) for battery electric vehicle (BEV) users. Research in Transportation Economics 82, 1000880. DOI: 10.1016/j.retrec.2020.100880.

[4] Bienias, K., Kowalska-Pyzalska A. \& Ramsey D. (2020). What do people think about electric vehicles? An initial study of the opinions of car purchasers in Poland. Energy Reports 6(1), 267-273. DOI: 10.1016/j.egyr.2019.08.055.

[5] Rota, M., Carcedo, J. \& García, J. (2016). Dual approach for modelling demand saturation levels in the automobile market. The Gompertz curve: Macro versus micro data. Investigación Económica 75(296), 43-72. DOI: 10.1016/j.inveco.2016.07.003.

[6] Nykvist, B. \& Nilsson, M. (2015). Rapidly falling costs of battery packs for electric vehicles. Nature climate change 5, 329-332. DOI: 10.1038/nclimate2564.

[7] Lerch, C., Kley, F. \& Dallinger, D. (2011). New business models for electric cars-A holistic approach. Energy policy 39(6), 3392-3403. DOI: 10.1016/j.enpol.2011.03.036.

[8] Long, Z., Axsen, J., Miller, J. \& Kormos, Ch. (2019). What does Tesla mean to car buyers? Exploring the role of automotive brand in perceptions of battery electric vehicles. Transportation Research Part A: Policy and Practice 129, 185-204. DOI: 10.1016/j.tra.2019.08.006.

[9] Kabát, L., Hampel, D., Issever Grochová, L, Janová, J. \& Střelec, L. (2014). Alternative Approaches for Assessing the European Countries Economic and Social Results. Procedia Economics and Finance 12, 273-282. DOI: 10.1016/S2212-5671(14)00345-1. 
[10] Staňková, M. \& Hampel, D. (2017). Identification of bankruptcy factors for engineering companies in the EU. In Mathematical Methods in Economics 2017: Conference Proceedings (pp.714-719). Hradec Králové: Univerzita Hradec Králové.

[11] Everitt, B.S., Landau, S., Leese, M. \& Stahl, D. (2011). Cluster Analysis (5th ed.). Hoboken, NJ: John Wiley \& Sons, Inc.

[12] Zámková, M. \& Blašková, V. (2013). Identification of factors affecting birth rate in Czech Republic. In SIMOS, T E. 11th International Conference of Numerical Analysis and Applied Mathematics 2013: ICNAAM 2013, AIP Conference Proceedings (pp. 1871-1874). Melville, New York: American Institute of Physics.

[13] Staňková, M. \& Hampel, D. (2018). Bankruptcy Prediction of Engineering Companies in the EU Using Classification Methods. Acta univ. agric. et silvic. Mendel. Brun. 66(5), 13471356. DOI: $10.11118 /$ actaun201866051347.

[14] Staňková, M. \& Hampel, D. (2021). On the influence of model setting on stochastic frontier analysis. Mathematical Methods in the Applied Sciences 44(1), 274-283. DOI: 10.1002/mma.6730.

[15] Střelec, L. \& Adamec, V. (2013). Exploration into power of homogeneity and serial correlation tests. Acta univ. agric. et silvic. Mendel. Brun. 61(4), 1129-1136. DOI: 10.11118/actaun201361041129.

[16] Dougherty, Ch. (2016). Introduction to Econometrics (5th ed.). Oxford: Oxford University Press.

[17] Urbanovský, T. (2017). Granger Causalities Between Interest Rate, Price Level, Money Supply and Real GDP in the Czech Republic. Acta univ. agric. et silvic. Mendel. Brun. 65(2), 745-757. DOI: 10.11118/actaun201765020745.

[18] Gujarati, D.N. \& Porter, D.C. (2017). Basic Econometrics (5th ed.). Boston: McGraw-Hill Education.

[19] Meckling, J. \& Nahm, J. (2017). When do states disrupt industries? Electric cars in Germany and the United States. MIT Center for Energy and Environmental Policy Research, Working Paper, 6.

[20] Stojanová, H., Lietavcova, B. \& Raguž, I. V. (2019). The dependence of unemployment of the senior workforce upon explanatory variables in the European Union in the context of Industry 4.0. Social Sciences, 8(1): 29. DOI: 10.3390/socsci8010029. 